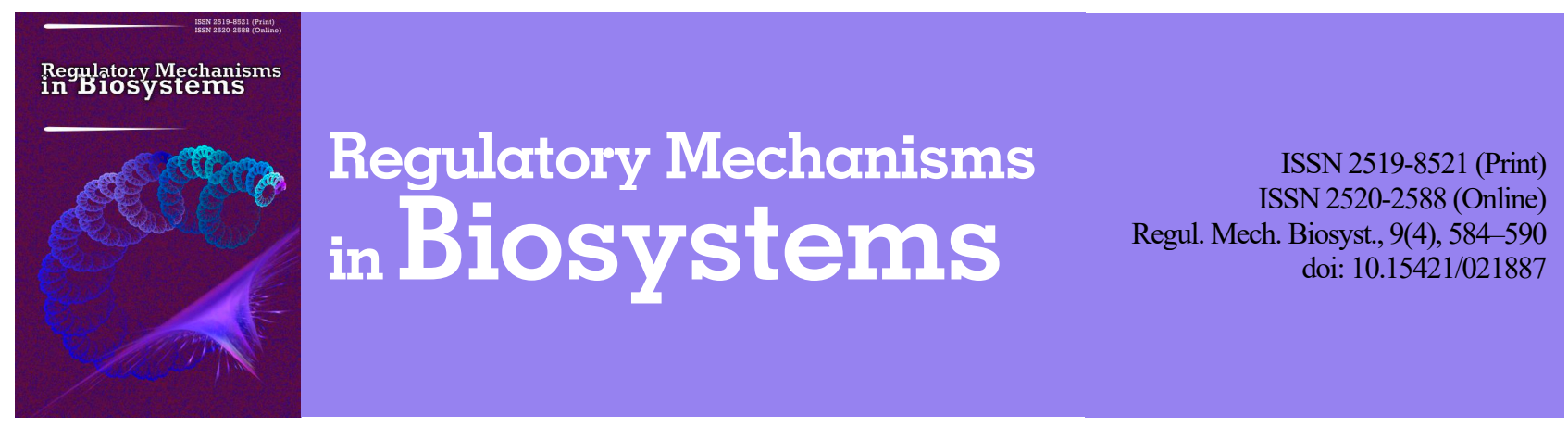

\title{
Enzyme protection systems of erythrocytes in conditions of ascorbate recirculation and oxidative loading
}

\author{
O. I. Dotsenko, G. V. Taradina, M. V. Voronych \\ Vasyl' Stus Donetsk National University, Vinnytsia, Ukraine
}

Article info

Received 16.10.2018

Received in revised form

12.11.2018

Accepted 16.11.2018

Vasyl' Stus Donetsk National University, 600-richya st., 21 ,

Vinnytsia, 21021, Ukraine Tel.: +38-093-724-66-10.

E-mail:dots_don@ukr.net

\section{Introduction}

Erythrocytes are the most important structures that prevent the irreversible degradation of dehydroascorbate (DHA). Concentration of ascorbate in erythrocytes is approximately equal to its concentration in plasma (Corti et al., 2010; Li et al., 2012; Witmer et al., 2016), that is, erythrocytes do not accumulate ascorbate, as opposed to white blood cells, where its content is two orders higher. The ability of erythrocytes to be permeable to DHA and to quickly reduce the latter is the most important condition for the long term preservation of the ascorbate pool in the body (Soumya \& Vani, 2017; Tu et al., 2017). In clinical samples, vitamin $C$ in plasma remains significantly longer, it is not detached from erythrocytes until the time of sample processing (Padayatty \& Levine, 2016). Plasma, in the absence of erythrocytes, loses vitamin $C$ very quickly unless special precautions are taken. In mammalian cells, ascorbates are the major donor of electrons involved in the reduction processes of both intracellular and extracellular metabolites (transmembrane electron transport). Stabilization of vitamin $\mathrm{C}$ in the plasma may be due to the transfer of electrons from ascorbic acid or NADH erythrocytes involving transmembrane proteins (Van Duijn et al., 2000; May et al., 2004; Su et al., 2006; Tu et al., 2017). These proteins are found in erythrocytes of species that are not able to form vitamin C, like humans, but they are absent in species that synthesize vitamin $\mathrm{C}$. It is possible that the transport of electrons through the membrane of erythrocytes is im- portant in diseases or conditions when the content of vitamin $\mathrm{C}$ in the plasma decreases, for example, diabetes mellitus (Tu et al., 2015; Padayatty \& Levine, 2016; Carelli-Alinovi \& Misiti, 2018). Recent studies have shown renewed interest in the use of pharmacological doses of vitamin $\mathrm{C}$ to save erythrocytes. It was shown that vitamin $\mathrm{C}$ partially protects erythrocytes from oxidative changes during storage, greatly reducing their mechanical fragility and hemolysis (Sanford et al., 2017; Soumya \& Vani, 2017). In addition, DHA can cause oxidative stress and death of cancer cells, so high doses of vitamin $\mathrm{C}$ could be potentially used in chemotherapy (Lu et al., 2018; O'Leary al., 2018). However, it was shown that erythrocytes can affect the efficacy of treatment by reducing the bioavailability of oral DHA (Zhang al., 2016).

Exogenous DHA in erythrocytes is involved in several oxidativereduction processes including regulation of hemoglobin, oxygen and its active forms contents, connected to the glutathione cell system. The content of reduced glutathione (GSH) and its correlation with oxidized glutathione (GSH/GSSG) is an indicator of oxidative stress (Pandey \& Rizvi, 2010; Maurya et al., 2015; Shan et al., 2015; Giustarini et al., 2017). Reduced glutathione (GSH) serves as a proton donor in reactions involving glutathione peroxidase (GP), glutathione transferase (GST), and ascorbate reductase. Reduced glutathione may also be a source of endogenous hydrogen peroxide. These reactions form an oxidized form of glutathione (GSSG). To support the oxidative-reducing state, GSSG cells are converted to GSH glutathione reductase (GR) using adenine 
dinucleotide phosphate nicotinamide (NADPH) as a proton donor. Glucose-6-phosphate dehydrogenase (G6PD) is an enzyme that limits the rate of NADPH generation. Under normal conditions, the cells have GR and NADPH supplements to support the GSH pool. However, under conditions of oxidative stress or in case of expression or activity deficiencies of GR or G6PD, the ability of cells to restore GSSG is reduced, resulting in accumulation of the oxidized form of glutathione in the cell.

The presence of transmembrane electronic transport systems in the erythrocyte plasma membrane provides cells with an additional level of protection from extracellular oxidants. Erythrocytes are known to reduce the number of extracellular oxidants, such as ferricyanide, methemoglobin, ferricytochrome $\mathrm{c}$ and monodehydroascorbyl radicals, using transmembrane transport of electrons. Exportation of electrons through a cell membrane was associated with the activity of the trans-membrane NADH dehydrogenase (EC 1.6.99.3) (May et al., 1996), which transports electrons from cytoplasmic NADH to extracellular acceptors. The common features of all membrane-associated oxidoreductases are the use of intracellular restorers, and the activity of these systems is closely related to the metabolic state of erythrocyte (Matteucci \& Giampietro, 2007). Thus, the quality of restoration of the DHA will be significantly dependent on the possibilities of the oxidative-reducing fermentation system and the state of erythrocyte hemoglobin. The processes associated with the accumulation of DHA inside the cells and the concentration gradient reduction of the latter between plasma and erythrocyte cytosol will inevitably lead to a decrease in the rate of DHA restoration, irreversible vitamin $\mathrm{C}$ deficiency and diseases.

Therefore, this work investigates changes in the content of reduced glutathione in time, the enzymes activity of the glutathione system, the state of the erythrocytes membrane electron transport system under the conditions of ascorbate recirculation and oxidative load. A small amount of $\mathrm{Cu}^{2+}$ was added to the incubation medium of erythrocytes to initiate the oxygen active forms generation and rapid DHA formation. It is known that the erythrocyte membrane and membrane-associated proteins are involved in electron transfer by oxidation of intracellular electron donors (e.g. ascorbate and NADH), thus exchange of electrons and maintenance of plasma components in a restored state (Kuhn et al., 2017). The state of these enzymes will determine the possibilities for transporting electrons. In this regard, we also investigate the effect of o-phenanthroline (o-phen). It is known that o-phen forms stable chelation complexes with copper ions, which have powerful oxidizing properties. By binding to the surface of the membrane, these compounds cause a decrease in the content of GSH, SH groups of proteins, formation of cross-links due to -S-S- bonds, protein aggregation of band 3 and spectrin (Hiroshigge, 1980; Tousova et al., 2004), which is the cause of morphological changes in erythrocytes. We considered that adding o-phen to the incubation environment would create additional burden on the erythrocytes glutathione system and affect the transmembrane transport of electrons. To simplify the analysis, glucose depletion was used to avoid the processes associated with the transport of glucose and DHA (they compete for the same transporter (Tu et al., 2017), as well as the effects of glycosylation and glucose reduce products.

\section{Materials and methods}

Study of radical-generating systems. In solutions, composed of (1) ascorbic acid (AscH) $1,0 \cdot 10^{-4} \mathrm{M}, \mathrm{Cu}^{2+}-5 \cdot 10^{-6} \mathrm{M}$, Na-phosphate buffer (0.015 M, pH 7.4) containing $0.15 \mathrm{M} \mathrm{NaCl}$ (buffer solution 1) and composed of (2) AscH $1.0 \cdot 10^{-4} \mathrm{M}, \mathrm{Cu}^{2+}-5.0 \cdot 10^{-6}$, o-phenanthroline $1.0 \cdot 10^{-4} \mathrm{M}$ and buffer solution 1, at certain intervals the hydrogen peroxide content was determined using a Fox reagent (Ou \& Wolff, 1996). When $\mathrm{H}_{2} \mathrm{O}_{2}$ or a medium containing $\mathrm{H}_{2} \mathrm{O}_{2}$ is introduced to a FOX reagent, $\mathrm{Fe}^{2+}$ is oxidized to $\mathrm{Fe}^{3+}$, the complex of the latter with xylenol orange has a maximum absorption at $560 \mathrm{~nm}$. The content of $\mathrm{H}_{2} \mathrm{O}_{2}$ in the sample was determined by calibration.

Study of the effect of radical-generating systems on the condition of the system of erythrocyte glutathione and the membrane electron transport. Peripheral blood of practically healthy donors of one sex and about one age was used. Erythrocytes were washed three times with centrifugation in a buffer solution. Plasma was washed out and packed erythrocytes were resuspended in the same buffer. Erythrocytes were incubated for 5 hours at $25^{\circ} \mathrm{C}$ in oxidizing media of composition 1 and 2 , described above. The number of erythrocytes in the incubation medium was maintained at a level of $2.1-2.6 \mathrm{mg} / \mathrm{l}$ hemoglobin content. At selected intervals, the samples were washed by centrifugation with buffer 1 . The washed erythrocytes were subjected to lysis by adding $0.01 \mathrm{M}$ Na-K-phosphate buffer ( $\mathrm{pH} 7.4$ ) containing $0.01 \%$ saponin.

The activity of the antioxidant enzymes of the glutathione system, the activity of the membrane-bound NADH:ferricyanide reductase and the content of reduced glutathione (GSH) were determined in the received hemolysate. As control, the activity of enzymes and the level of GSH in erythrocytes that were not exposed to radical-generating systems and contained in a buffer solution 1 were used.

Glutathione reductase activity (GR, EC 1.6.4.2) was studied according to the method described in (Mannervik, 2001). The principle of the method is to record the oxidation rate of NADPH in the presence of oxidized glutathione (GSSG) at $340 \mathrm{~nm}$. At the same time, the rate of NADPH oxidation in the absence of GSSG was recorded, allowing for NADPH that is oxidized by NADPH oxidase to be taken into account. The activity of GR was expressed in $\mu \mathrm{M}$ of $\mathrm{NADPH}$, converted in minutes per $\mathrm{mg}$ of $\mathrm{Hb}$, using the coefficient of molar extinction for NADPH $6220 \mathrm{M}^{-1} \cdot \mathrm{sm}^{-1}$.

Glutathione-S-transferase (GST, EC 2.5.1.18) activity was determined as described (Chikezie, 2011). The principle of method is based on the enzymatic coupling of reduced glutathione with 1-chloro-2,4-dinitrobenzene to form S-(2,4-dinitrophenyl)-glutathione, which has a maximum absorption at a wavelength of $340 \mathrm{~nm}$. The GST activity was calculated using a molar absorbance coefficient for a product of $9600 \mathrm{M}^{-1} \cdot \mathrm{sm}^{-1}$. Activity was expressed in $\mu \mathrm{M} / \mathrm{min} \cdot \mathrm{mg} \mathrm{Hb}$.

Glutathione peroxidase (GP, EC 1.11.1.9) activity was determined by the rate of reduced glutathione (GSH) oxidation in the presence of $\mathrm{H}_{2} \mathrm{O}_{2}$ (Razygrayev \& Arutyunyan, 2006). The amount of GSH after stopping the reaction was determined photometrically $(412 \mathrm{~nm})$ using the colour reaction based on the interaction between $\mathrm{SH}$-groups with the 5,5'-dithiobis (2-nitrobenzoic acid), resulting in a coloured product, thionitrophenyl anion.

Glucose-6-phosphate dehydrogenase (G6PD, EC 1.6.4.2) activity of was determined by the rate of recovery of NADP to NADPH, the content of which was recorded at a wavelength of $340 \mathrm{~nm}$ (Dotsenko, 2015). The activity of G6PD was expressed in $\mu \mathrm{M}$ of NADPH, which was produced in minutes per $\mathrm{mg}$ of $\mathrm{Hb}$, using a molar coefficient of extinction equal to $6220 \mathrm{M}^{-1} \cdot \mathrm{sm}^{-1}$.

Membrane-bound NADH:ferricyanide reductase activity was measured in red cell ghosts using a ferricyanide method at the rate of reduction of potassium ferricyanide in the presence of NADH. The activity of the enzyme was expressed as $\mu \mathrm{M}$ of reduced $\mathrm{K}_{3}\left[\mathrm{Fe}(\mathrm{CN})_{6}\right]\left(\varepsilon=1020 \mathrm{M}^{-1}\right.$. $\mathrm{sm}^{-1}, \lambda=400 \mathrm{~nm}$ ) per minute per $\mathrm{mg} \mathrm{Hb}$ (Crane et al., 1982).

Assay of GSH content. The washed erythrocytes were lysed in $0.5 \mathrm{ml}$ of cold water, after that $2.5 \mathrm{ml}$ of a precipitating mixture $(19.6 \mathrm{ml}$ of $85 \%$ orthophosphoric acid, 2 EDTA, $50 \mathrm{~g}$ of $\mathrm{NaCl}$ in $500 \mathrm{ml}$ of water) was added. The samples were thoroughly mixed and after 20 minutes of room temperature incubation centrifuged for 10 minutes. In the supernatant, the GSH content was determined with the Elman reagent. The optical density of the solution was measured at a wavelength $412 \mathrm{~nm}$. The content of GSH $(\mu \mathrm{M})$ was determined using a gauge dependence constructed for reduced glutathione with well-known concentrations. The content of GSH in erythrocytes was normalized on $\mathrm{mg}$ of $\mathrm{Hb}$ in the sample.

The hemoglobin content in erythrocytes was determined by a standard method.

\section{Results}

The dynamics of $\mathrm{H}_{2} \mathrm{O}_{2}$ accumulation in systems that are able to produce oxygen active forms (OAF) are shown in Fig. 1. In the $\mathrm{Cu}^{2+}$ AscH system the $\mathrm{H}_{2} \mathrm{O}_{2}$ content increases over time and reaches $43.6 \pm$ $0.87 \mu \mathrm{M}$ in 5 hours from the start of the reaction (Fig. 1). Adding ophenantroline to the system $\mathrm{Cu}^{2+}$-AscH increased by $2.0-2.5$ times the content of $\mathrm{H}_{2} \mathrm{O}_{2}$ in the system during the first reaction hour compared to the $\mathrm{Cu}^{2+}-\mathrm{AscH}$ alone. After that the production of $\mathrm{H}_{2} \mathrm{O}_{2}$ decreased but 
remained higher than in the $\mathrm{Cu}^{2+}$-AscH system. Thus, radical-generating systems 1 and 2 could be used as prooxidant systems models and for free radical oxidation processes initiation.

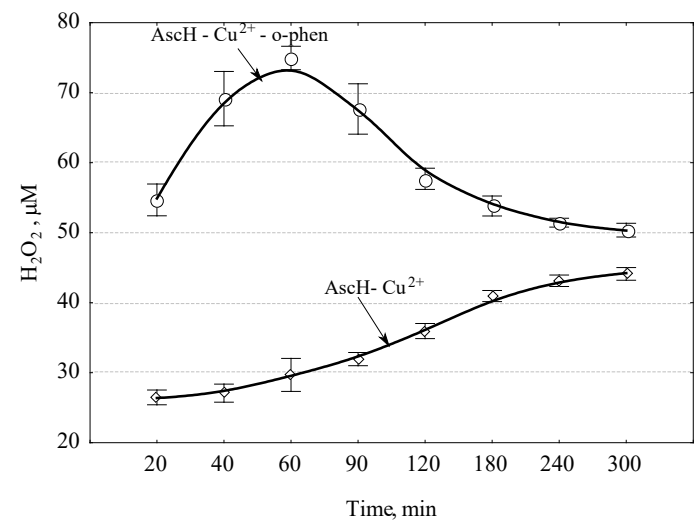

Fig. 1. $\mathrm{H}_{2} \mathrm{O}_{2}$ production in systems:

1 - ascorbic acid- $\mathrm{Cu}^{2+} ; 2$ - ascorbic acid- $\mathrm{Cu} 2+-$ o-phenanthroline

The pattern of GP and GST activity changes in erythrocytes incubated for five hours in $\mathrm{AscH}-\mathrm{Cu}^{2+}$ and $\mathrm{AscH}-\mathrm{Cu}^{2+}$ o-phen systems are shown in Figure $2 a, b$. GP and GST activities changes in erythrocytes under the influence of processes occurring in the $\mathrm{AscH}-\mathrm{Cu}^{2+}$ system have similar dynamics, with the only difference that in 90 minutes from the beginning of the experiment, the GST activity increased 1.6 times relative to the level of control, when the GP activity increased 6 times. The obtained experimental data confirm the fact that glutathione peroxidase has the pivotal role in the inactivation of OAF particularly hydrogen peroxide. Significant increase in GP activity indicates that erythrocytes accumulate $\mathrm{H}_{2} \mathrm{O}_{2}$, which can be exogenous or formed in erythrocytes during the hemoglobin and glutathione oxidation. After 90 minutes from the beginning of the experiment, the activity of the GP decreased and reached the control level after 4 hours of incubation, and the GST activity remained much higher than control until the end of the experiment (Fig. 2).

The GSH content in cells decreased during the first 90 minutes (Fig. 3a). After 90 minutes from the beginning of the experiment, a sharp increase of reduced glutathione was recorded, that cannot be attributed to an increase in the activity of GR, which controls the oxidized form of glutathione reduction by NADPH. The activity of this enzyme for erythrocytes in the $\mathrm{AscH}-\mathrm{Cu}^{2+}$ medium tended to decrease (Fig. $3 b$ ).

The nature of the change in GP activity in the $\mathrm{AscH} \mathrm{C \textrm {Cu } ^ { 2 + }}$ o-phen system was the same as in the $\mathrm{AscH}-\mathrm{Cu}^{2+}$ system, with the difference that enzyme activation took place somewhat earlier, with later decline of activity (Fig. 2a). The activity of GST erythrocytes that were treated with an o-phen medium for an hour from the beginning of the experiment remained at the control level, although there was a tendency to its increase (Fig. 2b). GST activity increased only after one and a half hour from the beginning of the experiment and in five hours its level was 1.6 times higher than control. GR reacted to the presence of stress agents similarly (Fig. 3b). The activity of this enzyme remained at the control level for an hour, and then sharply decreased, however, the level of activity of GR in system 2 remained higher than in system 1 .

The pattern of the G6PD activity change in erythrocytes incubated in systems 1 and 2 is shown in Figure 4a. During the incubation, the activity of G6PD in erythrocytes decreased to a greater extent in the system containing o-phen.

The dynamics of membrane-bound NADH:ferriyanide reductase activity change in erythrocytes treated with systems 1 and 2 is shown in Figure $4 b$. After 20 minutes from the beginning of the experiment, the membrane-bound NADH:ferriyanide reductase activity decreased by $71.7 \pm 14.7 \%$ in system 1 and by $48.8 \pm 18.4 \%$ in system 2 and maintained at this level for the next 90 minutes. After 2 hours from the beginning of the experiment, the activity of the enzyme began to increase. For erythrocytes in the system 1, the activity of membrane-bound NADH:ferriyanide reductase was almost completely restored, while the activity of the same enzyme in erythrocytes treated with medium 2 was not fully recovered and remained at $58.3 \pm 11.5 \%$ lower than control level.
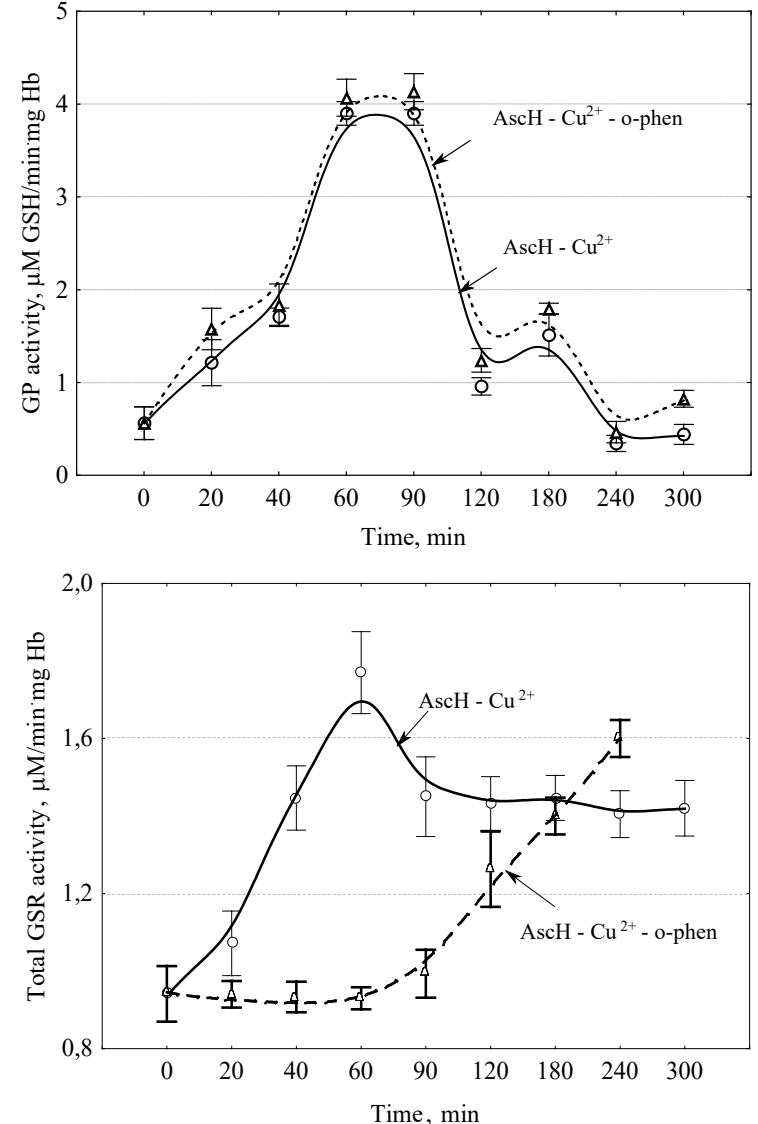

Fig. 2. GP $(a)$ and GST $(b)$ in erythrocytes treated with ascorbic acid $-\mathrm{Cu}^{2+}$ and ascorbic acid $-\mathrm{Cu}^{2+}-\mathrm{o}$-phenanthroline

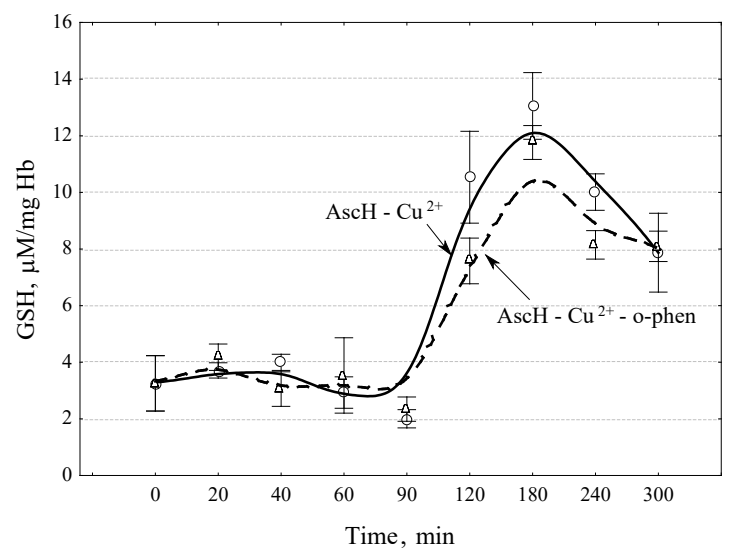

$a$

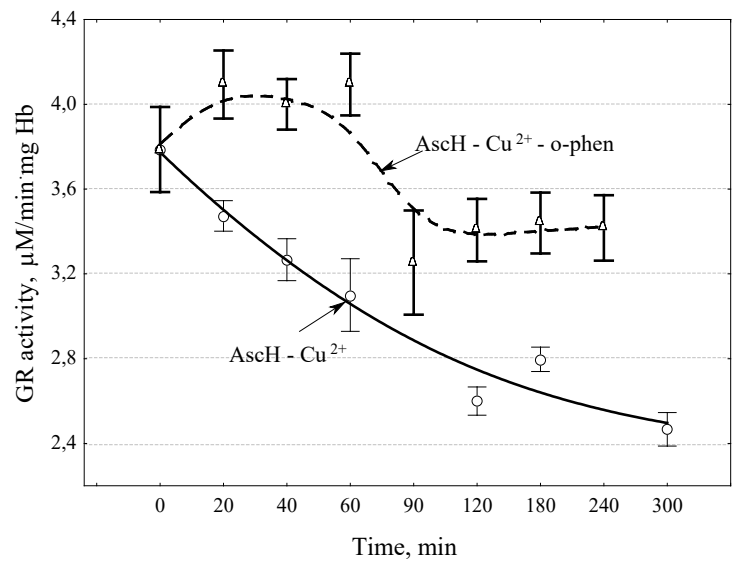

Fig. 3. GSH content $(a)$ and GR activity $(b)$ in erythrocytes treated with ascorbic acid $-\mathrm{Cu}^{2+}$ and ascorbic acid $-\mathrm{Cu}^{2+}-\mathrm{o}$-phenanthroline 


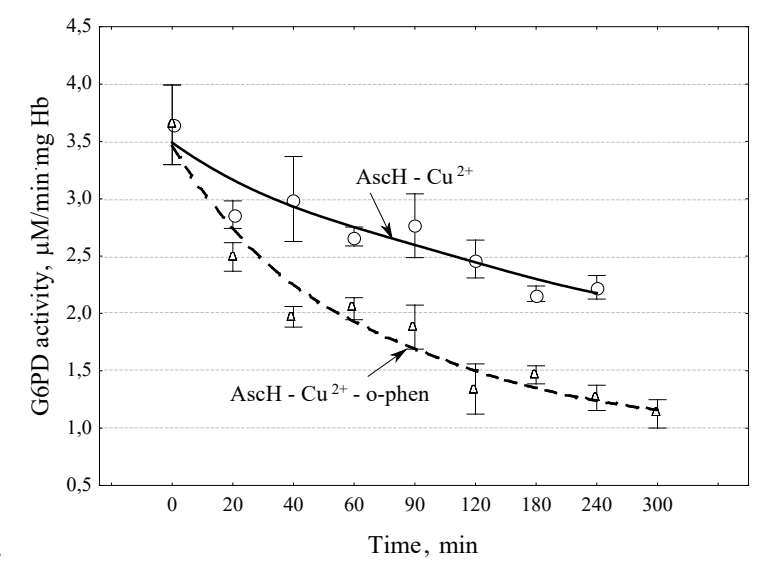

$a$

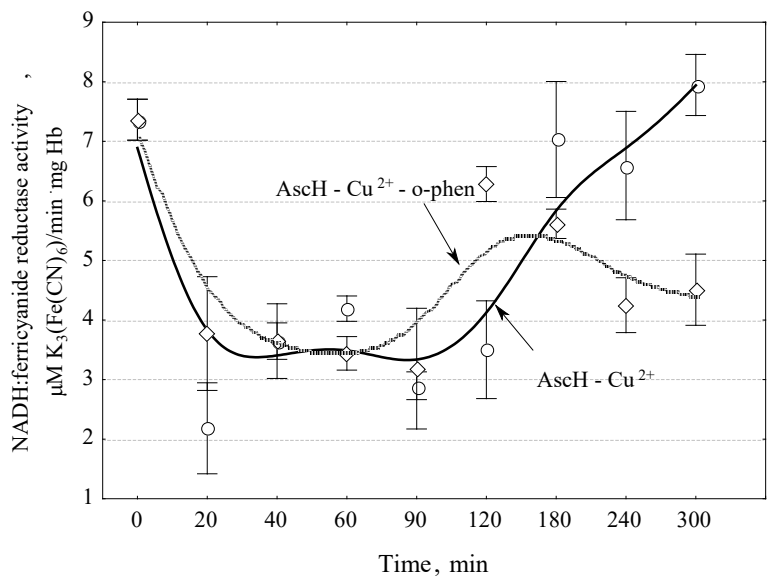

Fig. 4. G6PD ( $a$ ) Ta NADH:ferricyanide reductase (b) activity in erythrocytes treated with ascorbic acid $-\mathrm{Cu}^{2+}$ and ascorbic acid $-\mathrm{Cu}^{2+}-\mathrm{o}$-phenanthroline

\section{Discussion}

The first part of this paper investigates the efficiency of reactive oxygen species generation in systems that were subsequently used as an environment for the red blood cells incubation.

The $\mathrm{Cu}^{2+}-$ AscH system generates reactive oxygen species $\left(\mathrm{H}_{2} \mathrm{O}_{2}\right.$, $\cdot \mathrm{OH}^{-}, \mathrm{O}^{2-}$ ) sufficiently effectively during a long period. AscH reduces $\mathrm{Cu}^{2+}$ to $\mathrm{Cu}^{+}$in a water environment with the reaction rate constant $3.5 \mathrm{M}^{-1} \cdot \mathrm{s}^{-1}$ (Xu \& Jordan, 1990). The ions of monovalent copper can be incorporated into the Haber-Weiss and Fenton reactions (Scarpa, 1996), where the hydroxyl radicals are formed $\left(\cdot \mathrm{OH}^{-}\right)$. Notably, the rate constant of ROS production is very high $\left(4.7 \cdot 10^{3} \mathrm{M}^{-1} \cdot \mathrm{s}^{-1}\right)$ for $\mathrm{Cu}^{2+}$ ions interacting with $\mathrm{H}_{2} \mathrm{O}_{2}$ in Fenton reaction (for a similar system with $\left.\mathrm{Fe}^{2+}-76 \mathrm{M}^{-1} \cdot \mathrm{s}^{-1}\right)$. Then $\mathrm{Cu}^{+}$ions are oxidized to $\mathrm{Cu}^{2+}$, and those may further be reduced to $\mathrm{Cu}^{+}$by the ascorbate ions. The new formed monodehydroascorbyl radical and dehydroascorbate are capable of oxidizing $\mathrm{Cu}^{+}$to $\mathrm{Cu}^{2+}$. This cycle could run endlessly in theory, but some portions of dehydroascorbic acid also may be transformed into 2,3-diketogulonic acid irreversibly.

It is known that o-phenantroline is a chelating ligand and with $\mathrm{Cu}^{2+}$ ions it forms the coordination complexes $[\mathrm{Cu}(\mathrm{o}-\mathrm{phen})]^{2+}$ and $[\mathrm{Cu}(\mathrm{o}-$ phen $\left.)_{2}\right]^{2+}$. Coordination complexes of $\mathrm{Cu}^{2+}$ and o-phenantroline possess unique properties to provide a sufficiently effective catalysis of oxygennation reactions. They are used as the oxidase and oxygenase models in oxidation reactions with molecular oxygen. The solutions are saturated with oxygen with a concentration of $\mathrm{O}_{2}$ approximate $10^{-4} \mathrm{M}$. The reaction mechanism includes the coordination of the oxidizing substrate and oxygen in the axial positions of the metal complex with the intermediate formation of the triple complex. This facilitates the activation of molecular oxygen and accelerates the oxidation reaction. Obviously, the accumulation of $\mathrm{H}_{2} \mathrm{O}_{2}$ in the $\mathrm{AscH}-\mathrm{Cu}^{2+}-\mathrm{O}$-phen system is accelerating with the catalyst and is limited by the amount of reaction substrate, i.e. ascorbic acid.
Previously we investigated the dynamics of $\mathrm{H}_{2} \mathrm{O}_{2}$ accumulation in such systems in the presence of red blood cells (Dotsenko et al., 2010). We registered the presence of $\mathrm{H}_{2} \mathrm{O}_{2}$ in extracellular environment with $\mathrm{AscH}-\mathrm{Cu}^{2+}$ during the whole experiment time, while in the AscH$\mathrm{Cu}^{2+}-\mathrm{o}$-phen system the content of hydrogen peroxide decreased rapidly almost to zero because of the inability to coordinate substrates after binding $\left[\mathrm{Cu}(\mathrm{o}-\mathrm{phen})_{2}\right]^{2+}$ complexes with the red blood cells membranes.

Erythrocytes are cells with various functional features and are constantly exposed to oxidative stress. Normal hemoglobin may be involved in many pathological reactions under certain conditions. Even to perform the basic functions of binding, transport and release of oxygen in tissues, the cycling between oxy- and deoxy- and carboxy-states is required. In fully functional hemoglobin iron is always in $\mathrm{Fe}^{2+}$ state. The oxidation of $\mathrm{Fe}^{2+}$ to $\mathrm{Fe}^{3+}$ changes the hemoglobin properties - it acquires a strong oxidation quality. The reactions between hemoglobin and inorganic peroxides, such as $\mathrm{H}_{2} \mathrm{O}_{2}$ are also important. That type of reaction, which can occur in vivo, provides ferryl- and globin radicals and, consequently, peroxide oxidation of membrane lipids. In this regard, red blood cells are particularly well equipped with powerful enzymatic antioxidant systems that are important for maintenance of hemoglobin in the reduced state, to limit the oxidative modification of lipid membranes, structural proteins, channels, and metabolic enzymes (Soumya \& Vani, 2017). In addition, the antioxidant pathways of red blood cells and their ability to recover extracellular antioxidants through the transmembrane electron transport system make them an ideal component of the buffer antioxidant system that can contribute to the overall systemic oxidative-reducing homeostasis (Pandey \& Rizvi, 2010; Padayatty \& Levine, 2016). The disturbance or dysfunction of the antioxidant system can have serious effects on the cell, including the loss of membrane integrity.

The latest in vitro and in vivo studies showed that exogenous ascorbate effectively decreases the amount of ferrihemoglobin (methemoglobin) and globin radicals in blood plasma. And oxidized forms of ascorbate are effectively converted with the red blood cells participation. Monodehydroascorbyl radicals formed in these reactions could be reduced due to the reductase associated with the red blood cell membrane (May et al., 2004; Padayatty \& Levine, 2016; Tu et al., 2017). The ascorbate in erythrocytes is required for the structural integrity of these cells and can only be obtained through transport of DHA, while internal erythrocyte ascorbate is necessary to maintain the concentration of ascorbate in plasma in vitro/in vivo (Kennett \& Kuchel, 2006).

Therefore, in the second part of the study, we investigate the effect of ascorbate on the metabolic processes which maintain the viability of red blood cells. Most studies (Vani et al., 2015; Sanford et al., 2017; Soumya \& Vani, 2017) investigate the effect of ascorbate on erythrocytes over a significant amount of time, which is appropriate for their presservation. We shortened the study time by introducing a small amount of $\mathrm{Cu}^{2+}$ ions, which quickly trigger not only the formation of ascorbyl radicals, dehydroascorbate and its recycling, but also the formation of hydrogen peroxide and active forms of oxygen. Transport proteins and electron transport systems performances are greatly dependent on the state of the erythrocyte plasma membrane. Therefore o-phen was added to the incubation solution, complexes of which with $\mathrm{Cu}^{2+}$ modify the $\mathrm{SH}$-groups to -S-S- groups, increasing the rigidity of the erythrocyte membrane. In this paper, we analyze the content of glutathione in erythrocytes, the activity of the enzyme system of glutathione and membranebound NADH:ferricyanide reductase, which carries out an electron transport function.

The obtained data indicate that the red blood cells under the influence of the oxidative medium undergo significant oxidative stress. During the first treatment period of erythrocytes with the $\mathrm{AscH}-\mathrm{Cu}^{2+}$, the activity of GP and GST reaches maximal values, which indicates the presence of $\mathrm{H}_{2} \mathrm{O}_{2}$ in the cell and the activation of lipid peroxidation processes (Chikezie, 2011; Soumya \& Vani, 2017). GST is known to be induced by toxic electrophilic metabolites, therefore, activity growth can indicate the accumulation of the latter in the cell. $\mathrm{H}_{2} \mathrm{O}_{2}$ entering the cells from the outside is a two-electron oxidant: in the reaction with ferric-hemoglobin it will use one electron to oxidize ferric-heme into ferryl-heme $\left(\mathrm{Fe}^{\mathrm{IV}}=\mathrm{O}\right)$ and the other electron will oxidize the protein, 
generating a globin tyrosyl-based radical (Svistunenko et al., 2002). Products of hemoglobin oxidation have a high reactivity to membrane lipids, resulting in their oxidation. In the AscH-Cu ${ }^{2+}$ system with the participation of hemoglobin, active forms of oxygen and hydrogen peroxide, the processes of peroxide oxidation were activated rather quickly (Fig. 2b). GP and GST use GSH to protect red blood cells from toxic metabolites, so its content was reduced. Noticeably, the GSH content may also be decreased due to autooxidation processes and dehydroascorbate reduction that is transported into the cell with GSHdependent dehydroascorbate reductase (Xu et al., 1996).

GSH content is restored by GR and G6PD activity. The main function of GR is to reduce the oxidized form of glutathione (GSSG) using NADPH supplied by G6PD. In red blood cells, NADPH is important for oxidative stress protection. The main role of NADPH is to maintain the content of reduced glutathione (GSH) in a ratio greater than $500: 1$ over the oxidized form of GSSG (Arese et al., 2012). According to our data, the activity of these enzymes under the given conditions of incubation is reduced. The decrease in the activity of GR (Fig. $3 a$ ) potentially happens due to two reasons: first, there is no glucose in the incubation environment, resulting in a decrease in the rate of glycolysis and flow through the pentose phosphate pathway in which NADPH is regenerated, and second, the catalytic activity of GR is strongly dependent on the state of SH-groups (Dotsenko, 2015), which are easily subjected to oxidative modification. The decrease in G6PD activity is expected, as glucose does not reach the cells, and glucose-6-phosphate, which is the substrate of the reaction, is exhausted. Some post-translational modifications of the protein molecule may contribute to the decrease in the activity of the enzyme. Modifications caused by VROs include aggregation, polymerization, and oxidation of free SH-groups. However, as we can see, the decrease in G6PD activity does not exceed $29 \%$, which indicates the inclusion of alternative ways to support a carbohydrate pool. The glyceraldehyde-3-phosphate formed in the pentose phosphate pathway (PPP) may return to the glycolytic pathway and become a glucose-6-phosphate in three consecutive reactive reactions that are catalyzed by aldolase, phosphofructokinase, and phosphoglyucosomerase. The studies (Rinalducci et al., 2015; Reisz et al., 2016) confirmed the metabolic reprogramming in erythrocytes due to the decrease in the activity of glyceraldehyde-3-phosphate dehydrogenase (GAPDH) for the oxidation of the functional residues of the enzyme under the action of $\mathrm{H}_{2} \mathrm{O}_{2}$. In oxidative conditions, GAPDH promotes the formation of a glycolytic bottleneck, which results in the redirection of the metabolic flow to the pentosephobous pathway. In turn, in erythrocytes, in the presence of o-phen- $\mathrm{Cu}^{2+}$ complexes in the medium, surface rearrangements and cross-linking of membrane proteins, mainly spectrin and band 3, are observed, and the level of the hemichrome is increased. Aldolase, phosphofructokinase and glyceraldehyde-3-phosphate dehydrogenase are enzymes associated with the band 3. In the free state, the activity of these enzymes is higher than in the linked one. The decrease in G6PD activity by more than $57 \%$ in the presence of o-phen- $\mathrm{Cu}^{2+}$ complexes is possible if the activity of GAPDH, aldolase, phosphofructokinase is higher than in the $\mathrm{AscH}-\mathrm{Cu}^{2+}$ system, and flow is redirected mostly to the glycolytic pathway. Reducing the activity of G6PD leads to a deficiency of NADPH, which causes a decrease in GR activity and the content of reduced glutathione.

A sharp increase in GSH can occur by protein deglutathionylation, that is, the release of GSH from mixed disulfides formed with redoxsensitive Cys residues of proteins (P-S-SG). Deglutathionylation processes are initiated by intracellular redox status (changes in GSH/GSSG ratio, hemoglobin oxidation) or by enzymatic reduction mediated by glutaredoxin (Grx), GR, the thioredoxin/thioredoxin reductase (Trx/TrxR) system, or sulfiredoxin (Srx). Another pathway for the deglutathionylation of $\mathrm{Hb}$ mediated mainly by conformational changes induced by $\mathrm{CO}$ binding with hemoglobin (Metere et al., 2014). CO is one of the products of degradation of hem under the influence of OAF. These degradation products may initiate oxidative processes in erythrocytes, but at low concentrations, they have cytoprotective properties. When linked to the membrane, $\mathrm{COHb}$ activates the pentose-phosphate pathway, which contributes to the additional formation of GSH. It has been shown (Metere et al., 2014) that GAPDH and possibly other glycolytic enzymes (phosphofructokinase, aldolase, pyruvate kinase and lactate dehydrogenase) are not released in their activated form in the cytoplasm from band 3 protein. Prevention of flow in the glycolytic pathway, and rotation of the flow at the level of glyceraldehyde-3-phosphate in the pentose phosphate pathway, allows NADPH to be maintained in erythrocytes in the absence of glucose. Research (Rinalducci et al., 2015; Reisz et al., 2016) has confirmed the metabolic reprogramming in erythrocytes, but the main role in these processes was deletion of GAPDH, which could decrease its activity by oxidizing the functional residues of Cys. The decrease in GAPDH activity may be the first step that helps to stabilize the level of NADPH and glutathione under conditions of sufficient cellular resistance to oxidative loading. In particular, the oxidation modification of sulfhydryl groups in proteins is a two-way process that may lead to deterioration of the protein function or, depending on the oxidation-reducing state of cysteine residues, may activate specific ways of regulating the basic functions of cells (Vani et al., 2015). Further CO-dependent growth of GSH in erythrocytes and additional activation of PPP can support the activity of GR and G6PD at lower, but not critical levels for the cell.

Changes in the activity of membrane-bound NADH:ferricyanide reductase completely coincide with our analysis of redistribution of metabolic flows and was also discussed by other authors (Kennett \& Kuchel, 2006; Matteucci \& Giampietro, 2007). The decrease in the activity of the enzyme is consistent with the accumulation of OAF in the extracellular and intracellular medium (Dotsenko et al., 2010). This reductase for the recovery of the extracellular electron acceptor uses intraocular $\mathrm{NADH}$, which is formed only in the reaction that catalyzes glyceraldehyde-3-phosphate dehydrogenase. The decline in the activity of this enzyme discussed above leads to a decrease in the content of NADH and, as a consequence, loss of NADH:ferricyanide reductase activity. Restoring the flow through the glycolytic pathway will help increase the NADH:ferricyanide reductase activity, which is observed in the experiment. Gradual restoration of the activity of membrane-bound NADH: ferricyanide reductase coincides with a sharp increase in GSH in erythrocytes. Authors studying GAPDH (Rinalducci et al., 2015; Reisz et al., 2016) noted the reversibility of the oxidation of SH groups and the possibility of increasing the activity of this enzyme. The increase in GAPDH activity allows the flow to return to the glycolytic pathway, increasing the content of NADH, ATP and lactate, but this results in a decrease in the content of NADPH and glutathione. Perhaps there is a vibrational process, the direction of which is determined by the ratio on the one hand of NADPH/NADP, GSH/GSSG, and on the other of $\mathrm{NADH} / \mathrm{NAD}, \mathrm{ATP} /(\mathrm{ADP}+\mathrm{AMP})$. The trigger that switches the flow is membrane-bound hemoglobin - carboxyhemoglobin (under hypoxia and oxidative loading) / deoxyhemoglobin.

The increase in the activity of membrane-bound NADH:ferricyanide reductase of erythrocytes in the $\mathrm{AscH}-\mathrm{Cu}^{2+}$ system suggests that the level of ascorbate outside the cell is restored. But the processes of peroxidation are not diminished, since the activity of GST far exceeds the level of control. The sulfhydryl site of the membrane-bound NADH:ferricyanide reductase is found on the outer surface of the cell (May et al., 1996; Kennett \& Kuchel, 2006; Matteucci \& Giampietro, 2007). The presence of $[\mathrm{Cu}(\mathrm{o}-\mathrm{phen})]^{2+}$ and $\left[\mathrm{Cu}(\mathrm{o}-\mathrm{phen})_{2}\right]^{2+}$ complexes causes its modification, due to the disulfide bridges formation. It is known that the transmembrane NADH:ferricyanide reductase has two binding sites, with the NADH binding centre located in the cell, and the centre sensitive to ferricyanide, located externally. In this case, the access of ferricyanide to the binding site will be complicated.

In the incubation system, $\mathrm{AscH}-\mathrm{Cu}^{2+}-\mathrm{o}-\mathrm{phen} \mathrm{Cu}^{2+}$ ions are found in the phenanthroline complexes that are sorbed on the membrane, oxidizing the surface SH-groups, initiating the formation of the -S-S-strand. The dehydroascorbate transporter Glutl is blocked, since it has SHgroups involved in transporting metabolites. If the movement of DHA to erythrocytes is complicated, then it will accumulate in the extracellular medium and switch to 2,3-diketogulonic acid. Increasing the rigidity of the erythrocyte membrane, the aggregation of the band 3 protein (Hiroshigge, 1980; von Rückmann \& Schubert, 2002), very low levels of $\mathrm{H}_{2} \mathrm{O}_{2}$ in the cell and outside the cell (Dotsenko et al., 2010) may slow down the oxidative processes in the cell and oxidize lipids Therefore, for erythrocytes exposed to the environment with o-phen, we observed 
some differences in the altered activity of enzymes, which generally indicate that oxidative stress develops later (the effect of o-phenanthroline complexes $\mathrm{Cu}^{2+}$ on the state of SH-groups of the membrane leads to the development of oxidative stress). The oxidative modification of SH groups of membrane-bound NADH:ferricyanide reductase is likely to reduce the ascorbic acid content in the extracellular medium and accumulate oxidized forms of ascorbate. This point should be taken into account when applying antioxidants (such as flavonoids) and medicines that can form chelates with metal ions.

\section{Conclusion}

Erythrocytes under the influence of media containing ascorbate and $\mathrm{Cu}^{2+}$ ions, ascorbate and o-phen- $\mathrm{Cu}^{2+}$ complexes in the absence of glucose undergo oxidative stress, as evidenced by the pattern of the change in glutathione content, the activities of the glutathione system key enzymes and membrane-bound NADH:ferricyanide reductase. Our study revealed the role of metabolic reprogramming in erythrocytes through thioldisulfide exchange and CO-signaling pathway of hemoglobin deglutathionylation as mechanisms that can be included in adaptive responses aimed at counteracting stress states in mammalian cells and tissues.

\section{References}

Arese, P., Gallo, V., Pantaleo, A., \& Turrini, F. (2012). Life and death of glucose6-phosphate dehydrogenase (G6PD) deficient erythrocytes - role of redox stress and band 3 modifications. Transfusion Medicine and Hemotherapy, 39(5), 328-334.

Dotsenko, O. I., Dragushenko, O. O., \& Dotsenko, V. A. (2010). The investigation of the action of prooxidant and cytotoxic systems $\mathrm{Cu}^{2+}-\mathrm{AscH}, \mathrm{Cu}^{2+}$ AscH-o-phenanthroline [Doslidzhennia prooksydantnoi ta tsytotoksychnoi dii system $\mathrm{Cu}^{2+}-\mathrm{AscH}, \mathrm{Cu}^{2+}-\mathrm{AscH}-\mathrm{o}$-phenanthroline]. Dosiahnennia Biolohii ta Medytsyny, 15(1), 1-7 (in Ukrainian).

Dotsenko, O. I. (2015). Glutathione system's activity in the blood of mice in the conditions of vibration stress [Aktivnost' sistemy glutationa krovi myshej, nahodjashhihsja v uslovijah vibracionnogo stressa]. ScienceRise, 11(16), 39 46 (in Russian).

Carelli-Alinovi, C., \& Misiti, F. (2017). Erythrocytes as potential link between diabetes and Alzheimer's disease. Frontiers in Aging Neuroscience, 25(9), 276-286.

Chikezie, C. P. (2011). Glutathione S-transferase activity of human erythrocytes incubated in aqueous solutions of five antimalarial drugs. Free Radicals and Antioxidants, 1(2), 26-30.

Corti, A., Casini, A. F., \& Pompella, A. (2010). Cellular pathways for transport and efflux of ascorbate and dehydroascorbate. Archives of Biochemistry and Biophysics, 500, 107-115.

Giustarini, D., Colombo, G., Garavaglia, M. L., Astori, E., Portinaro, N. M., Reggiani, F., Badalamenti, S., Aloisi, A. M., Santucci, A., Rossi, R., Milzani, A., \& Dalle-Donne, I. (2017). Assessment of glutathione/glutathione disulphide ratio and S-glutathionylated proteins in human blood, solid tissues, and cultured cells. Free Radical Biology and Medicine, 112, 360-375.

Crane, F. L., Crane, H. E., Sun, I. L., MacKellar, W. C., Grebing, C., \& Löw, H. (1982). Insulin control of a transplasma membrane NADH dehydrogenase in erythrocyte membranes. Journal of Bioenergetics and Biomembranes, $14(5-6), 425-433$.

Hiroshige, Y. (1980). The effects of copper and copper-o-phenanthroline complex on the intact human erythrocytes. The Tohoku Journal of Experimental Medicine, 130, 385-402.

Kennett, E. C., \& Kuchel, P. W. (2006). Plasma membrane oxidoreductases: Effects on erythrocyte metabolism and redox homeostasis. Antioxidants and Redox Signaling, 8(7-8), 1241-1247.

Kuhn, V., Diederich, L., Keller, T. C. S. IV, Kramer, C. M., Lückstädt, W., Panknin, C., Suvorava, T., Isakson, B. E., Kelm, M., \& Cortese-Krott, M. M. (2017). Red blood cell function and dysfunction: Redox regulation, nitric oxide metabolism, anemia. Antioxidants and Redox Signaling, 26(13), 718-742.

Li, H., Tu, H., Wang, Y., \& Levine, M. (2012). Vitamin C in mouse and human red blood cells: An HPLC assay. Analytical Biochemistry, 426(2), 109-117.

Lu, Y. X., Wu, Q. N., Chen, D. L., Chen, L. Z., Wang, Z. X., Ren, C., Mo, H. Y., Chen, Y., Sheng, H., Wang, Y. N., Wang, Y., Lu, J. H., Wang, D. S., Zeng, Z. L., Wang, F., Wang, F. H., Li, Y. H., Ju, H. Q., \& Xu, R. H. (2018). Pharmacological ascorbate suppresses growth of gastric cancer cells with GLUT1. Overexpression and enhances the efficacy of oxaliplatin through redox modulation. Theranostics, 8(5), 1312-1326.

Mannervik, B. (2001). Measurement of glutathione reductase activity. Current Protocols in Toxicology, 7, 7.2.
Matteucci, E., \& Giampietro, O. (2007). Electron pathways through erythrocyte plasma membrane in human physiology and pathology: Potential redox biomarker? Biomarker Insights, 2, 321-329.

Maurya, P. K., Kumar, P., \& Chandra, P. (2015). Biomarkers of oxidative stress in erythrocytes as a function of human age. World Journal of Methodology, 5(4), 216-222.

May, J. M., Qu, Z.-C., \& Morrow, J. D. (1996). Interaction of ascorbate and $\alpha$ tocopherol in resealed human erythrocyte ghosts: Transmembrane electron transfer and protection from lipid peroxidation. The Journal of Biological Chemistry, 271, 10577-10582.

May, J. M., Qu, Z. C., \& Cobb, C. E. (2004). Human erythrocyte recycling of ascorbic acid: Relative contributions from the ascorbate free radical and dehydroascorbic acid. Journal of Biological Chemistry, 279(15), 1497514982.

Metere, A., Iorio, E., Scorza, G., Camerini, S., Casella, M., Crescenzi, M, Minetti, M., \& Pietraforte, D. (2014). Carbon monoxide signaling in human red blood cells: Evidence for pentose phosphate pathway activation and protein deglutathionylation. Antioxidants and Redox Signaling, 20(3), 403-416.

O'Leary, B. R., Houwen, F. K., Johnson, C. L., Allen, B. G., Mezhir, J. J., Berg, D. J., Cullen, J. J., \& Spitz, D. R. (2018). Pharmacological ascorbate as an adjuvant for enhancing radiation-chemotherapy responses in gastric adenocarcinoma. Radiation Research, 189(5), 456-465.

Ou, P., \& Wolff, S. P. (1996). A discontinuous method for catalase determination at 'near physiological' concentrations of $\mathrm{H}_{2} \mathrm{O}_{2}$ and its application to the study of $\mathrm{H}_{2} \mathrm{O}_{2}$ fluxes within cells. Journal of Biochemical and Biophysical Methods, 31(1-2), 59-67.

Pandey, K. B., \& Rizvi, S. I. (2010). Markers of oxidative stress in erythrocytes and plasma during aging in humans. Oxidative Medicine and Cellular Longevity, 3(1), 2-12.

Padayatty, S. J., \& Levine, M. (2016). Vitamin C: The known and the unknown and goldilocks. Oral Diseases, 22(6), 463-493.

Razygrayev, A. V., \& Arutyunyan, A. V. (2006). Determination of human serum glutathione peroxidase activity, by using hydrogen peroxide and 5,5'-dithiobis (2-nitrobenzoic acid) [Opredelenie glutationperoksidaznoj aktivnosti $\mathrm{v}$ syvorotke krovi cheloveka s ispol'zovaniem peroksida vodoroda i 5,5'ditiobis(2-nitrobenzojnoj kisloty)]. Klinicheskaia Laboratornaia Diagnostika, 6, 13-16 (in Russian).

Reisz, J. A., Wither, M. J., Dzieciatkowska, M., Nemkov, T., Issaian, A., Yoshida, T., Dunham, A. J., Hill, R. C., Hansen, K. C., \& D'Alessandro, A. (2016). Oxidative modifications of glyceraldehyde 3-phosphate dehydrogenase regulate metabolic reprogramming of stored red blood cells. Blood, 128(12), 32-42.

Rinalducci, S., Marrocco, C., \& Zolla, L. (2015) Thiol-based regulation of glyceraldehyde-3-phosphate dehydrogenase in blood bank-stored red blood cells: A strategy to counteract oxidative stress. Transfusion, 55(3), 499-506.

Sanford, K., Fisher, B. J., Fowler, E., Fowler, A. A., \& Natarajan, R. (2017). Attenuation of red blood cell storage lesions with vitamin C. Antioxidants (Basel), 6(3), e55.

Shan, G., Yang, F., Zhou, L., Tang, T., Okoro, E. U., Yang, H., \& Guo, Z. (2015). Increase in blood glutathione and erythrocyte proteins related to glutathione generation, reduction and utilization in African-American old women with diabetes. Journal of Environmental Science and Technology, 5(1), 3000251.

Scarpa, M. (1996). Ascorbate oxidation catalyzed by bis(histidine) copper (II). Inorganic Chemistry, 35(18), 5201-5206.

Soumya, R., \& Vani, R. (2017). Vitamin C as a modulator of oxidative stress in erythrocytes of stored blood. Acta Haematologica Polonica, 48(4), 350-356.

Svistunenko, D. A., Dunne, J., Fryer, M., Nicholls, P., Reeder, B. J., Wilson, M. T., Bigotti, M. G., Cutruzzolà, F., \& Cooper, C. E. (2002) Comparative study of tyrosine radicals in hemoglobin and myoglobins treated with hydrogen peroxide. Biophysical Journal, 83(5), 2845-2855.

Su, D., May, J. M., Koury, M. J., \& Asard, H. (2006). Human erythrocyte membranes contain a cytochrome b561 that may be involved in extracellular ascorbate recycling. Journal of Biological Chemistry, 281, 39852-39859.

Tousova, K., Susankova, K., Teisinger, J., Vyklicky, L., \& Vlachova, V. (2004). Oxidizing reagent copper-o-phenanthroline is an open channel blocker of the vanilloid receptor TRPV1. Neuropharmacology, 47(2), 273-285.

Tu, H., Li, H., Wang, Y., Niyyati, M., Wang, Y., Leshin, J., \& Levine, M. (2015). Low red blood cell vitamin $\mathrm{C}$ concentrations induce red blood cell fragility: A link to diabetes via glucose, glucose transporters, and dehydroascorbic acid. EBioMedicine, 2(11), 1735-1750.

Tu, H., Wang, Y., Li, H., Brinster, L. R., \& Levine, M. (2017). Chemical transport knockout for oxidized vitamin $\mathrm{C}$, dehydroascorbic acid, reveals its functions in vivo. EBioMedicine, 23, 125-135.

VanDuijn, M. M., Tijssen, K., VanSteveninck, J., Van Den Broek, P. J., \& Van Der Zee, J. (2000). Erythrocytes reduce extracellular ascorbate free radicals using intracellular ascorbate as an electron donor. Journal of Biological Chemistry, 275, 27720-27725. 
Vani, R., Soumya, R., Carl, H., Chandni, V. A., Neha, K., Pankhuri, B., Trishna, S., \& Vatsal, D. P. (2015). Prospects of vitamin C as an additive in plasma of stored blood. Advances in Hematology, 4, 961049.

Witmer, J. R., Wetherell, B. J., Wagner, B. A., Du, J., Cullen, J. J., \& Buettner, G. R. (2016). Direct spectrophotometric measurement of supra-physiological levels of ascorbate in plasma. Redox Biology, 8, 298-304.

Xu, D. P., Washburn, M. P., Sun, G. P., \& Wells, W. W. (1996). Purification and characterization of a glutathione dependent dehydroascorbate reductase from human erythrocytes. Biochemical and Biophysical Research Communications, 221(1), 117-121

Xu, J., \& Jordan, R. B. (1990). Kinetics and mechanism of the reaction of aqueous copper (II) with ascorbic acid. Inorganic Chemistry, 29(16), 2933-2936.

Zhang, Z. Z., Lee, E. E., Sudderth, J., Yue, Y., Zia, A., Glass, D., Deberardinis, R. J., \& Wang, R. C. (2016). Glutathione depletion, pentose phosphate pathway activation, and hemolysis in erythrocytes protecting cancer cells from vitamin C-induced oxidative Stress. Journal of Biological Chemistry, 291(44), 22861-22867. 